\title{
Creating idiometric short-form measures of cognitive appraisal: balancing theory and pragmatics
}

\author{
Carolyn E. Schwartz ${ }^{1,2^{*}}$, Roland B. Stark ${ }^{1}$ and Bruce D. Rapkin ${ }^{3}$
}

\begin{abstract}
Background: The Rapkin and Schwartz appraisal theory and measure provided a path toward documenting response-shift effects and describing individual differences in ways of thinking about quality of life (QOL) that distinguished people in different circumstances. Recent work developed and validated the QOL Appraisal Profile $_{\text {version } 2}\left(\mathrm{QOLAP}_{\mathrm{v} 2}\right)$, an 85-item measure that taps response-shift-detection domains of Frame of Reference, Standards of Comparison, Sampling of Experience, and Combinatory Algorithm. Recent theoretical work proposed that appraisal measurement constitutes a new class of measurement (idiometric), distinct from psychometric and clinimetric. To validate an idiometric measure, one would document that its items reflect different circumstances and population characteristics, and explain variance in QOL. The present work sought to develop idiometric shortforms of the QOLAP $P_{v 2}$ item bank by examining which items were most informative, retaining the appraisal-domain structure.
\end{abstract}

Methods: This secondary analysis $(n=1481)$ included chronically-ill patients and their caregivers from a longitudinal web-based survey (mean follow-up 16.6 months). Data included the QOLAP $\mathrm{v}_{\mathrm{v}}$, the Center for Disease Control Healthy Days Core Module, the PROMIS-10 Global Health, and demographic/medical variables. Appraisal items were measured at baseline (relevant to understanding cognitive appraisal processes); and with change scores (sensitive to response-shift effects). Multivariate analysis of covariance examined what demographic and health-status change variables were reflected by each of 85 appraisal items (in five sets), as dependent variables, and other demographic/ medical variables. Multiple linear regression examined how appraisal items explained variance in global physicaland mental-health change, after covariate adjustment. A tally summarized item performance across all five sets of cross-sectional and longitudinal analyses.

Results: The vast majority (i.e., 80\%) of the QOLAP $\mathrm{v2}$ items performed well across the analyses presented. Using a relatively strict criterion of explaining meaningful variance across $60 \%$ of analyses, one would retain 68 items. A more lenient criterion (40\%) would retain 71.

Conclusions: The present study provides heuristics to support investigators' creating 'discretionary' QOLAP $\mathrm{v}_{\mathrm{v} 2}$ shortforms to fit their study aim and amplifying individual differences in the cognitive processes underlying QOL. This approach enables adapting the measure to the study population, as per the expectation that respondent populations differ in the predominant cognitive processes used.

Keywords: Appraisal, Response shift, Individual differences, Cognitive, Measurement, Idiometric

\footnotetext{
* Correspondence: carolyn.schwartz@deltaquest.org

'DeltaQuest Foundation, Inc., 31 Mitchell Road, Concord, MA 01742, USA

${ }^{2}$ Departments of Medicine and Orthopaedic Surgery, Tufts University Medical

School, Boston, MA, USA

Full list of author information is available at the end of the article
}

\section{Springer Open}

(c) The Author(s). 2021 Open Access This article is licensed under a Creative Commons Attribution 4.0 International License, which permits use, sharing, adaptation, distribution and reproduction in any medium or format, as long as you give appropriate credit to the original author(s) and the source, provide a link to the Creative Commons licence, and indicate if changes were made. The images or other third party material in this article are included in the article's Creative Commons licence, unless indicated otherwise in a credit line to the material. If material is not included in the article's Creative Commons licence and your intended use is not permitted by statutory regulation or exceeds the permitted use, you will need to obtain permission directly from the copyright holder. To view a copy of this licence, visit http://creativecommons.org/licenses/by/4.0/. 


\section{Background}

The study of response-shift phenomena has been facilitated over the past 25 years by response-shift theory $[1-3]$ and related methodological development [4-11]. While many response-shift-detection methods rely only on quantitative analysis of patterns suggestive of response shift (e.g., measurement invariance [5, $11]$ ), there are also several methods that combine qualitative and quantitative characterization of response-shift effects (e.g., Schedule for the Evaluation of Individual Quality of Life [12], Patient-Generated Index [13], Quality of Life Appraisal Profile (QOLAP) [2]). Rapkin and Schwartz introduced in 2004 a more testable version of the Sprangers and Schwartz response-shift theoretical model [1] and the QOLAP $[2,14]$. The QOLAP combined open- and closedended questions to characterize individual differences in four domains necessary for characterizing response-shift effects: Frame of Reference comprised of Quality of Life (QOL) Definition and Goal Delineation; Standards of Comparison; Sampling of Experience; and Combinatory Algorithm [2]. Building on Tourangeau's [15] theoretical and empirical work on the psychology of survey response, the Rapkin and Schwartz appraisal theory and initial measure provided a path toward not only documenting responseshift effects $[2,3,16]$, but also describing the differences in ways of thinking about QOL and patterns of emphasis that distinguished people who fared better or worse with chronic medical conditions such as human immunodeficiency virus [7], multiple sclerosis [17], bladder cancer [18], and spinal disorders [19].

The four appraisal domains are elements of the contingent true score described in Schwartz and Rapkin [14]. In this formulation, any rating of a QOL item reflects a latent QOL "true score" that is contingent upon processes of QOL appraisal. Thus, numerical agreement in QOL scores does not guarantee that respondents arrived at their responses in the same way [14]. Two respondents may both rate themselves as doing poorly but base their conclusion on different observations [14]. Understanding these differences in appraisal fosters better communication between patient and caregiver and increases our ability to predict or explain QOL scores [14]. Characterizing changes in appraisal enables detection of responseshift effects. Specifically, changes in Standards of Comparison reflect recalibration; changes in Sampling of Experience and/or Combinatory Algorithm reflect reprioritization; and changes in Frame of Reference reflect reconceptualization [2].

In an effort to make the collection of QOL-appraisal data more feasible, Rapkin and Schwartz developed and validated two closed-ended measures [20, 21]. The QOLAP version $2\left(\mathrm{QOLAP}_{\mathrm{v} 2}\right)$ [20] includes 85 items and taps the four abovementioned domains. This measure has the advantage of retaining the theoretical foundation and having closed-ended items that are less resource-intensive than the original mixed-method QOLAP. The Brief Appraisal Inventory (BAI) [21] was created to be a parsimonious appraisal measure that emphasized the most prominent patterns found in our appraisal research to date [22-24], but it did not aim to represent equally the four appraisal domains. While one can evaluate general response-shift effects using the BAI, one cannot characterize the three aspects of response shift (recalibration, reprioritization, reconceptualization [2]) because the four appraisal domains are not fully captured by the BAI [3].

\section{Appraisal measures are idiometric}

Since the original 2004 papers [2, 14], our group has come to a better understanding of the nature of appraisal measurement [25]. Specifically, appraisal tools are idiometric. Accordingly, the items aim to reflect a broad range of possible attitudes/behaviors that inter-correlate in expected and meaningful ways, and which differ across individuals/groups and within individuals/groups over time. With this goal, appraisal measures contrast with psychometric measures, which aim to assess a universal latent construct. Appraisal measures also contrast with those of clinimetric measures, which aim to identify an underlying clinical phenomenon [25]. For a full description of the theoretical distinctions, statistical implications, and clinical applications that characterize idiometric versus psychometric and clinimetric measures, the interested reader is referred to [25].

\section{Reflecting versus explaining variance}

Besides the separate ways in which appraisal at baseline and appraisal change scores can address QOL comparisons and response-shift detection, respectively, we draw another distinction. Ways of appraising QOL can both reflect and explain variance in other constructs. Seen in the role of reflecting variance, appraisal can reveal both universal and circumstantial aspects of experience [25]. In other words, both antecedents (stable characteristics of the individual) and catalysts (health-state changes, life events, etc.). can affect appraisal, revealing the universal and contextual aspects of experience. This role is shown most naturally when appraisal is used as a dependent variable in a model. For example, we would expect alignment of personal goals with cultural norms for age and gender (universal aspect), while there may be differences in the importance of accomplishing work goals among people facing disruptive life events, such as the diagnosis of new illness or becoming a grandparent (circumstantial). 
Seen in the role of explaining variance, appraisal can provide an important context for comparing QOL scores across individuals, both cross-sectionally and over time. As noted above, shared appraisal processes underlie a contingent true score, enabling comparison across individuals [14]. Appraisal change over time serves a separate function, that of revealing response-shift effects in QOL discrepancy scores [2, 3]. In this role of explaining variance, appraisal would most naturally serve as an independent variable in a model. It may also moderate the effect of other independent variables. For example, the emotional impact of multiple chronic health conditions is generally known (universal), but its impact on a particular individual may depend on whether his/her Standards of Comparison focus on others with similar health conditions versus how they were when they were younger (circumstantial).

\section{Criteria for creating a short-form of an idiometric measure}

An idiometric measure would be considered effective if it either reflected variance or explained variance related to individual differences in circumstances and experience. Accordingly, creating a short form of an appraisal tool would thus proceed differently than it would for a psychometric tool (e.g., focus on unidimensionality, internal consistency, consistent structure across samples, etc.) or for a clinimetric tool (e.g., focus on relevance to diagnosing and/or distinguishing clinical phenomena) [25]. Such creation would seek to retain a broad universe of content by sampling from an appraisal item bank that encompasses the relevant multidimensional concepts. We would, for example, hypothesize that a measure of appraisal should look different for people at different developmental levels or with different socioeconomic contexts (i.e., different challenges to bear). It should look different for people who are working vs. retired, of different health status or level of wealth. We would select a parsimonious set of items on the basis of reflecting or explaining variance across QOL constructs and/or sociodemographic characteristics.

\section{Magnitude of effect}

In terms of effect-size (ES) metrics, we would consider important even those ES considered "small" [26]. Such "small" effects contribute to a better understanding of what matters to an individual's QOL at one point in time and over time. ES provides a generic metric of the magnitude of the effect, rather than a score or change score that is specific to the reported measure. ES is also less impacted by sample size, whereas $p$-values can be highly significant for negligibly small effects due to their sensitivity to sample size. Finally, small ES can amplify response-shift-adjusted estimates of treatment-related change [27], such that what was a small unadjusted treatment effect can become a medium ES when response-shift effects are considered - even small ones.

\section{Toward an idiometric appraisal short form}

In summary, an idiometric measure should reflect and/ or explain variance related to individual differences in circumstances and experience. Item selection for a short-form variant should focus on both such criteria, so that the eventual measure is useful not only for describing the relevant cognitive processes in a cross-sectional study, for example, but also for detecting response-shift effects in longitudinal data. Triangulating on the "best" items for an appraisal measure must rely on multiple criteria.

\section{Methods}

\section{Aim}

The present work thus sought to understand which QOLAP $_{\mathrm{v} 2}$ items were most informative so that one or more short-forms of the QOLAP $_{\mathrm{v} 2}$ could be developed, retaining the appraisal-domain structure.

\section{Sample}

This secondary analysis utilized data collected from Rare Patient Voice and WhatNext panels, with a heterogeneous grouping of chronic health conditions. These panel-research organizations recruit patients and caregivers representing over 200 diagnoses, by attending patient-advocacy conferences. This recruitment approach ensures that participants have or care for someone with the specified diagnosis. Participants sign up to be included in panels to facilitate research on the disease in question, participation for which they may be paid honoraria if resources permit. Eligible participants were patients or caregivers of someone with a chronic medical condition, age 18 years or older, and able to complete an online questionnaire. The present academic study was unfunded and thus unable to pay honoraria.

\section{Design and setting}

A web-based survey was administered twice (baseline, follow-up) using the Health Insurance Portability and Accountability Act (HIPAA)-compliant, secure Alchemer engine (www.alchemer.com). (See [28] for full description of baseline methods, and [16] for follow-up and selection-bias analyses.) The study was reviewed and approved by the New England Review Board (NEIRB\#15-254), and all participants provided informed consent.

\section{Measures}

The QOLAP ${ }_{\mathrm{v} 2}$ [20] is an 85-item measure of cognitiveappraisal processes invoked when answering QOL 
measures. Four domains are assessed using closed-ended rating-scale items with a response scale ranging from "not at all like me" (1) to "very much like me" (5) or "not applicable/decline" (-99). The Frame of Reference domain queries how the individual thinks about QOL [QOL Definition (20 items)] and what personal goals matter most to their QOL [Goal Delineation (33 items)]. Sampling of Experience (14 items) queries the individual's heuristics or criteria for responding to QOL measures. Standards of Comparison (9 items) queries to whom or what the individual compares him/herself to when thinking about QOL. Combinatory Algorithm (9 items) assesses the individual's patterns of emphasis, i.e., what aspects of QOL are considered more salient or more important than others. (The interested reader can contact the authors for a copy of the measure.)

Outcome Measures included the Center for Disease Control Healthy Days Core Module [29] and the PatientReported Outcome Measurement Information System (PROMIS) Global Short Form (PROMIS-10). The third item of the former asks how many days of the past 30 the respondent's poor physical or mental health kept them from doing their usual activities of daily living (ADL), such as self-care, work, or recreation. The PROMIS-10 yielded scores for global physical and global mental health [30].

Demographic / medical variables included in the analyses included age, gender, ethnicity, race, cohabitation/ marital status, with whom the person lives, employment status, disability status (i.e., binary variable indicating if disabled from employment), and difficulty paying bills [31]. Number of comorbidities was measured with the Self-Administered Comorbidity Questionnaire [32]. ZIP code was used to characterize in which region of the contiguous US the participant lived [33].

\section{Statistical analysis}

Two sets of analyses aimed at identifying items that 1) reflected diverse perspectives and/or 2) explained variability in health outcomes in the present sample. In both sets of analyses, we used appraisal items both at baseline and in change scores. Baseline appraisal is relevant to understanding cognitive processes at a given point in time, whereas change-in-appraisal scores are needed to detect response-shift effects per se [2, 3]. We also focused on three separate indicators of QOL change: change in activities of daily living, global physical health, and global mental health. Using QOL change indicators as dependent variables is central to response-shift studies. According to appraisal theory [2], response shift is inferred when change in appraisal explains the discrepancy between expected and observed change in QOL. This discrepancy is often operationalized as the residuals in a "standard QOL model," i.e., predicting QOL change after adjusting for sociodemographic and other characteristics [3]. As an independent variable, QOL change can help one see to what extent an appraisal item might account for variance in the QOL item. These two complementary approaches help to gauge the relevance of an appraisal item to individual circumstances.

\section{Reflecting variability}

To understand what demographic and health-status change variables were reflected by appraisal items, six separate multivariate multiple regressions used baseline appraisal or change-in-appraisal items by domain as dependent variables. Predictors included alternate indicators of QOL change (change in activities of daily living, global physical and mental health) and demographic characteristics (region, gender, age, comorbidities, difficulty paying bills, whether working, whether retired, whether disabled). We used a multivariate analysis of covariance (MANCOVA) procedure because predictors included both continuous and categorical variables and we wanted to evaluate all appraisal items within each domain in a single procedure. Even though we were not focusing on group differences, we still retain the label "MANCOVA" for ease of distinguishing from the multiple regression models described below.

\section{Explaining variability}

To understand how appraisal items explain variance in QOL outcomes, four separate multiple regression models were conducted for each appraisal item as an independent variable. In addition to baseline and changein-appraisal in separate models, independent variables included selected demographic covariates. Dependent variables were global physical and mental health. Via interactions, these covariates helped account for the expectation that a measure of appraisal will have different slopes for people at different developmental levels (age), different health status (comorbidity burden), or different socioeconomic contexts (difficulty paying bills). To avoid model overspecification, we chose these sociodemographic characteristics based on exploratory analyses of their ability to predict with at least a small effect size on average. We did not want to impede our ability to detect meaningful differences in change by using baseline scores as covariates. Generally speaking, baseline and follow-up QOL scores are often highly correlated and may share some of the same predictors, such as appraisal items. We did not want to rule out meaningful items due to this statistical artifact.

\section{Tally of results}

To summarize results across all 50 models, we noted those items that explained enough variance to constitute at least a small ES. A small ES for a dependent variable 
in a MANCOVA model would require an eta ${ }^{2}$ or $\mathrm{R}^{2}$ greater than 0.02 [26, 34]. A small ES for an individual predictor in a regression model would require an increment to eta ${ }^{2}$ or $\mathrm{R}^{2}$ of greater than 0.01 . Effect sizes (ES) of small, medium, and large magnitude using Cohen's criteria were shown using conditional formatting in tables via light, medium, and fully saturated highlighting.

Statistical assumptions and power The focus of the above-mentioned analyses is to evaluate the reflective and explanatory value of a large set of items, with an eye toward selecting a subset for inclusion in a recommended short-form. Parametric statistical methods are used and treat the rating-scale (ordinal) items as continuous. Although statistical orthodoxy suggests that ordinal data should be analyzed with non-parametric methods [35, 36], for parametric analytical methods, such as regression or analysis of variance, one commonly encounters judgments such as "individual rating items with numerical response formats at least five categories in length may generally be treated as continuous data." [37] (Also see [38].) Even moderate violations of parametric assumptions (i.e., of normal distributions, interval level of measurement, and homogeneity of variances) have been shown to have little or no effect on substantive conclusions in most instances [34]. Further, the testing of homogeneity of variances for methods such as regression or analysis of variance is generally performed when two or more samples are being compared [39], which is not the case in the present work [39]. Finally, we rely on the magnitude of total model explained variance, rather than the magnitude, direction, or $p$-values for predictors' coefficients, thereby further reducing the risk of inappropriate inference. Consequently, we utilize these parametric approaches and do not specifically test the assumptions of the 50 tested models. Readers interested in examining variable distributions are referred to Supplemental Table 1. Although as mentioned we do not focus on $p$-values, this study is, incidentally, more than well-powered to detect a small ES in the context of a multivariable linear model with eight covariates $(\alpha=$ 0.05; $\mathrm{N}$ required $=757$; actual $N=1391$ [26]). The focus of analyses is only on ES rather than p-value, due to the exploratory nature of the research question and the large number of analyses conducted.

Software Data analyses were implemented using SPSS version 26 [40] and the R software [41].

\section{Results \\ Sample}

The study's analytic sample included 1481 people, comprising 1212 patients, 227 caregivers, and 42 patientcaregivers. The sample represented 212 distinct diagnoses, ranging from rare conditions such as Marfan Syndrome $(n=2)$, which occurs in 1 in 5000 people, to more common medical illnesses such as Breast Cancer $(n=246)$ and Multiple Sclerosis $(n=217)$. Mean followup was 16.9 months (standard deviation $[\mathrm{SD}]=1.7$; range $=13.5-25.7$ ). Table 1 provides the reported sociodemographic characteristics and comorbidities of this heterogeneous sample. Supplemental Table 1 provides descriptive information about the items and QOL summary scores. Interested readers are referred to an indepth treatment of appraisal inter-item correlations across many populations, which provided the foundation for the "idiometric" distinction [25].

\section{Selection biases and missing data}

Previous reported analyses characterized selection biases in the longitudinal analytic sample [16]. Participants retained in the study were slightly older, less likely to be caregivers, more likely to have arthritis, and less likely to have an ulcer or stomach disease compared to those not retained. They were also more likely to be non-Hispanic, White, and slightly more educated; and to be/have been engaged in an occupation requiring extensive preparation. Out of 1481 participants, $0-7 \%$ were missing a value for any given variable included in a model, other than the appraisal item. In the case of region, where 7\% were missing values, we categorized such cases as "unknown" and incorporated that as a new category in analysis. The end result was a listwise $\mathrm{N}$ of 1391 for MANCOVAs and regressions, which meant $6.1 \%$ of cases were excluded in either type of procedure.

\section{Items that reflected or explained more variability}

Supplemental Tables 2 and 3 show results of preliminary exploratory analyses aimed at narrowing down a set of eight demographic predictors for the regression models. These tables supported retaining age, comorbidities, and difficulty paying bills.

Tables 2, 3, 4, 5 and 6 detail the results of MANCOVAs and regression models evaluating baseline and change items for each of the $\mathrm{QOLAP}_{\mathrm{v} 2}$ domains. Models evaluating baseline appraisal are relevant to understanding cognitive appraisal processes at a given point in time, whereas those addressing change-in-appraisal scores are more relevant to detecting response-shift effects per se. The value of keeping the three dependent variables of change in ADL, global physical and mental health separate is apparent in looking at patterns across Tables 2, 3, 4, 5 and 6. While some appraisal items perform similarly across outcomes, there are frequently differences between global mental health and the two other dependent variables. Further, there are distinct differences in explained variance when comparing models evaluating baseline appraisal versus appraisal change. This varied 
Table 1 Person-Level Demographic Characteristics ( $N=1481)$

\begin{tabular}{|c|c|c|}
\hline \multicolumn{3}{|l|}{ Variable } \\
\hline \multirow[t]{4}{*}{ Role } & Patient & $82 \%$ \\
\hline & Caregiver & $15 \%$ \\
\hline & Both & $3 \%$ \\
\hline & Missing & $0 \%$ \\
\hline Follow-Up Time (Months) & Mean (SD) & $16.9(1.7)$ \\
\hline Age & Mean (SD) & $49.9(13.2)$ \\
\hline Age at diagnosis & Mean (SD) & $41.1(17.2)$ \\
\hline Had help completing questionnaire & & $2 \%$ \\
\hline \multirow[t]{3}{*}{ Gender } & Male & $14 \%$ \\
\hline & Female & $86 \%$ \\
\hline & Missing & $0 \%$ \\
\hline \multirow[t]{9}{*}{ Number of comorbidities out of a possible 15} & 0 & $4 \%$ \\
\hline & 1 & $11 \%$ \\
\hline & 2 & $14 \%$ \\
\hline & 3 & $18 \%$ \\
\hline & 4 & $17 \%$ \\
\hline & 5 & $14 \%$ \\
\hline & 6 & $11 \%$ \\
\hline & 7 or more & $12 \%$ \\
\hline & Missing & $0 \%$ \\
\hline \multirow[t]{7}{*}{ Marital Status } & Never Married & $14 \%$ \\
\hline & Married & $61 \%$ \\
\hline & Cohabitation/ Domestic Partnership & $7 \%$ \\
\hline & Separated & $2 \%$ \\
\hline & Divorced & $12 \%$ \\
\hline & Widowed & $4 \%$ \\
\hline & Missing & $0 \%$ \\
\hline \multirow[t]{3}{*}{ Ethnicity (\%) } & Not Hispanic or Latino & $93 \%$ \\
\hline & Hispanic or Latino & $4 \%$ \\
\hline & Missing & $3 \%$ \\
\hline \multirow[t]{4}{*}{ Race (\%) } & Black or African American & $4 \%$ \\
\hline & White & $93 \%$ \\
\hline & Other & $1 \%$ \\
\hline & Missing & $2 \%$ \\
\hline \multirow[t]{8}{*}{ Income (\%) } & Less than $\$ 15,000$ & $8 \%$ \\
\hline & $\$ 15,001$ to $\$ 30,000$ & $14 \%$ \\
\hline & $\$ 30,001$ to $\$ 50,000$ & $17 \%$ \\
\hline & $\$ 50,001$ to $\$ 100,000$ & $29 \%$ \\
\hline & $\$ 100,001$ to $\$ 150,000$ & $13 \%$ \\
\hline & $\$ 150,001$ to 200,000 & $5 \%$ \\
\hline & Over $\$ 200,000$ & $3 \%$ \\
\hline & Missing & $12 \%$ \\
\hline \multirow[t]{2}{*}{ Region (named regions are in USA) } & East North Central & $18 \%$ \\
\hline & East South Central & $5 \%$ \\
\hline
\end{tabular}


Table 1 Person-Level Demographic Characteristics ( $N=1481)$ (Continued)

\begin{tabular}{|c|c|c|}
\hline \multicolumn{3}{|l|}{ Variable } \\
\hline & Middle Atlantic & $11 \%$ \\
\hline & Mountain & $7 \%$ \\
\hline & New England & $6 \%$ \\
\hline & Pacific & $14 \%$ \\
\hline & South Atlantic & $16 \%$ \\
\hline & West North Central & $7 \%$ \\
\hline & West South Central & $9 \%$ \\
\hline & Non-Contiguous & $1 \%$ \\
\hline & Other & $7 \%$ \\
\hline \multirow[t]{6}{*}{ Difficulty Paying Bills } & Not difficult at all & $36 \%$ \\
\hline & Slightly difficult & $23 \%$ \\
\hline & Somewhat difficult & $18 \%$ \\
\hline & Very difficult & $10 \%$ \\
\hline & Extremely difficult & $10 \%$ \\
\hline & Missing & $4 \%$ \\
\hline \multirow[t]{5}{*}{ Employment Status } & Employed & $48 \%$ \\
\hline & Unemployed & $11 \%$ \\
\hline & Retired & $13 \%$ \\
\hline & Disabled Due To Medical Condition & $27 \%$ \\
\hline & Missing & $1 \%$ \\
\hline Work Complexity (past or present) & Mean (SD), 1-5 scale & $3.3(1.1)$ \\
\hline \multirow[t]{6}{*}{ Education } & Some high school & $1 \%$ \\
\hline & High school diploma/GED & $20 \%$ \\
\hline & Technical or trade school degree & $18 \%$ \\
\hline & Bachelor's degree & $33 \%$ \\
\hline & Graduate or professional degree & $26 \%$ \\
\hline & Missing & $2 \%$ \\
\hline \multirow[t]{6}{*}{ Mother's Education } & Some high school & $13 \%$ \\
\hline & High school diploma/GED & $45 \%$ \\
\hline & Technical or trade school degree & $14 \%$ \\
\hline & Bachelor's degree & $17 \%$ \\
\hline & Graduate or professional degree & $9 \%$ \\
\hline & Missing & $2 \%$ \\
\hline \multirow[t]{6}{*}{ Father's Education } & Some high school & $14 \%$ \\
\hline & High school diploma/GED & $37 \%$ \\
\hline & Technical or trade school degree & $14 \%$ \\
\hline & Bachelor's degree & $16 \%$ \\
\hline & Graduate or professional degree & $14 \%$ \\
\hline & Missing & $5 \%$ \\
\hline
\end{tabular}

information is then summarized in a tally across QOLAP v2 domains (Table 7). We will summarize below the number of items showing small, medium, and large ES for baseline variability and sensitivity to response-shift effects (i.e., to change scores) for each domain. Supplementary Table 4 provides $95 \%$ confidence intervals for the explained variance estimates (i.e., eta ${ }^{2}$ and $R^{2)}$ of the MANCOVA and regression models. 
Table 2 Results of MANCOVA and Regression Analyses with Baseline and Change-Scores of QOL Definition Items in the Frame of Reference Domain $(n=1391)$

\begin{tabular}{|c|c|c|c|c|c|c|c|c|c|c|c|c|c|c|}
\hline \multicolumn{15}{|c|}{$\begin{array}{l}\text { Results of MANCOVA and Regression Analyses with Baseline and Change-Scores of QOL Definition Items in the Frame of Reference Domain } \\
\qquad(n=1,391)\end{array}$} \\
\hline & \multicolumn{2}{|c|}{$\begin{array}{l}\text { MANCOVA 1: Includes } \\
\text { among the } \\
\text { independent variables } \\
\text { Healthy Days ADL } \\
\text { change score* }\end{array}$} & \multicolumn{2}{|c|}{\begin{tabular}{|c|} 
MANCOVA 2: Includes \\
among the \\
independent variables \\
PROMIS Global \\
Physical Health change \\
score*
\end{tabular}} & \multicolumn{2}{|c|}{$\begin{array}{l}\text { MANCOVA 3: Includes } \\
\text { among the } \\
\text { independent variables } \\
\text { PROMIS Global Mental } \\
\text { Health change score* }\end{array}$} & \multicolumn{4}{|c|}{$\begin{array}{l}\text { Regression predicting PROMIS Global Physical } \\
\text { Health change scoret }\end{array}$} & \multicolumn{4}{|c|}{$\begin{array}{c}\text { Regression predicting PROMIS Global Mental } \\
\text { Health change score }{ }^{+}\end{array}$} \\
\hline \multirow[t]{2}{*}{ QOL Definition Item } & \multicolumn{2}{|c|}{$\mathrm{Eta}^{2}$} & \multicolumn{2}{|c|}{$\mathrm{Eta}^{2}$} & \multicolumn{2}{|c|}{$\mathrm{Eta}^{2}$} & \multicolumn{2}{|c|}{$\mathbf{R}^{2}$} & \multicolumn{2}{|c|}{$\begin{array}{c}\mathbf{R}^{2} \text { increment with } \\
\text { appraisal item }\end{array}$} & \multicolumn{2}{|c|}{$R^{2}$} & \multicolumn{2}{|c|}{$\begin{array}{c}R^{2} \text { increment with } \\
\text { appraisal item }\end{array}$} \\
\hline & $\begin{array}{l}\text { Baseline } \\
\text { Appraisal }\end{array}$ & $\begin{array}{l}\text { Change in } \\
\text { Appraisal }\end{array}$ & $\begin{array}{l}\text { Baseline } \\
\text { Appraisal }\end{array}$ & $\begin{array}{l}\text { Change in } \\
\text { Appraisal }\end{array}$ & $\begin{array}{c}\text { Baseline } \\
\text { Appraisal }\end{array}$ & $\begin{array}{l}\text { Change in } \\
\text { Appraisal }\end{array}$ & $\begin{array}{l}\text { Baseline } \\
\text { Appraisal }\end{array}$ & $\begin{array}{l}\text { Change in } \\
\text { Appraisal }\end{array}$ & $\begin{array}{l}\text { Baseline } \\
\text { Appraisal }\end{array}$ & $\begin{array}{l}\text { Change in } \\
\text { Appraisal }\end{array}$ & $\begin{array}{l}\text { Baseline } \\
\text { Appraisal }\end{array}$ & $\begin{array}{l}\text { Change in } \\
\text { Appraisal }\end{array}$ & $\begin{array}{l}\text { Baseline } \\
\text { Appraisal }\end{array}$ & $\begin{array}{l}\text { Change in } \\
\text { Appraisal }\end{array}$ \\
\hline Worry-free & 0.02 & NA & 0.02 & NA & 0.02 & NA & 0.09 & 0.09 & 0.00 & NA & 0.02 & 0.01 & 0.01 & NA \\
\hline Accomplish job & 0.37 & NA & 0.37 & NA & 0.37 & NA & 0.09 & 0.09 & 0.01 & NA & 0.01 & 0.01 & 0.00 & NA \\
\hline Well-off & 0.02 & NA & 0.03 & NA & 0.02 & NA & 0.09 & 0.09 & 0.01 & NA & 0.01 & 0.01 & 0.00 & NA \\
\hline Perfect health & 0.05 & NA & 0.05 & NA & 0.05 & NA & 0.09 & 0.09 & 0.00 & NA & 0.01 & 0.01 & 0.00 & NA \\
\hline Living for today & 0.02 & NA & 0.02 & NA & 0.02 & NA & 0.09 & 0.09 & 0.00 & NA & 0.01 & 0.01 & 0.00 & NA \\
\hline Family time & 0.03 & NA & 0.03 & NA & 0.03 & NA & 0.09 & 0.09 & 0.01 & NA & 0.01 & 0.01 & 0.00 & NA \\
\hline Not rely on others & 0.03 & NA & 0.03 & NA & 0.03 & NA & 0.09 & 0.09 & 0.01 & NA & 0.01 & 0.01 & 0.00 & NA \\
\hline Legacy & 0.01 & 0.02 & 0.01 & 0.02 & 0.01 & 0.02 & 0.09 & 0.09 & 0.00 & 0.00 & 0.02 & 0.01 & 0.01 & 0.00 \\
\hline Do for others & 0.02 & 0.03 & 0.02 & 0.03 & 0.02 & 0.03 & 0.09 & 0.09 & 0.00 & 0.00 & 0.02 & 0.02 & 0.00 & 0.01 \\
\hline Healthy lifestyle & 0.03 & 0.02 & 0.03 & 0.02 & 0.03 & 0.02 & 0.09 & 0.09 & 0.01 & 0.01 & 0.01 & 0.01 & 0.00 & 0.00 \\
\hline Faith & 0.05 & 0.02 & 0.05 & 0.02 & 0.05 & 0.02 & 0.09 & 0.09 & 0.00 & 0.00 & 0.01 & 0.01 & 0.00 & 0.00 \\
\hline Calm & 0.02 & 0.02 & 0.02 & 0.02 & 0.02 & 0.02 & 0.09 & 0.09 & 0.00 & 0.00 & 0.02 & 0.02 & 0.00 & 0.01 \\
\hline Independence & 0.03 & 0.03 & 0.03 & 0.03 & 0.03 & 0.03 & 0.09 & 0.09 & 0.01 & 0.01 & 0.01 & 0.01 & 0.00 & 0.00 \\
\hline No regret & 0.01 & 0.01 & 0.01 & 0.01 & 0.01 & 0.01 & 0.09 & 0.09 & 0.01 & 0.01 & 0.01 & 0.02 & 0.00 & 0.00 \\
\hline Children's successes & 0.02 & 0.01 & 0.03 & 0.01 & 0.02 & 0.01 & 0.09 & 0.09 & 0.00 & 0.00 & 0.02 & 0.02 & 0.00 & 0.00 \\
\hline Romance & 0.06 & 0.01 & 0.06 & 0.01 & 0.06 & 0.01 & 0.09 & 0.09 & 0.00 & 0.00 & 0.01 & 0.01 & 0.00 & 0.00 \\
\hline Leisure & 0.04 & 0.02 & 0.04 & 0.02 & 0.04 & 0.02 & 0.09 & 0.09 & 0.00 & 0.00 & 0.01 & 0.02 & 0.00 & 0.00 \\
\hline Responsibilities & 0.04 & 0.02 & 0.04 & 0.02 & 0.04 & 0.02 & 0.09 & 0.09 & 0.01 & 0.01 & 0.02 & 0.01 & 0.01 & 0.00 \\
\hline Family problems & 0.02 & 0.01 & 0.03 & 0.01 & 0.02 & 0.01 & 0.09 & 0.09 & 0.01 & 0.01 & 0.01 & 0.01 & 0.00 & 0.00 \\
\hline Accepting myself & 0.02 & 0.02 & 0.01 & 0.02 & 0.01 & 0.02 & 0.09 & 0.09 & 0.00 & 0.00 & 0.01 & 0.01 & 0.00 & 0.00 \\
\hline
\end{tabular}

Conditional formatting indicates the magnitude of the effect size (ES), with the least saturated highlighting showing small ES, the middle saturation indicating a medium ES, and the most saturated indicating a large ES

* Dependent variables: QOL Definition Items; Independent Variables: region, gender, age, comorbidities, difficulty paying bills, whether working, whether retired, whether disabled

† Independent Variables: QOL Definition item; 3 covariates -- age, comorbidities, difficulty paying bills; \& QOL Definition item's interactions with the covariates

\section{QOL-definition items}

Fifteen of the 20 baseline items and six of the 20 change scores explained at least a small ES of variance in the MANCOVAs (Table 2). Two baseline items and no change scores stood out in terms of explaining medium or large ESs. None of the items, however, explained substantial unique variance in the regression models predicting global physical or mental health.

\section{Goal-delineation items}

Thirty of the 33 baseline items and 29 of the 33 change scores explained at least a small ES of variance in the MANCOVAs (Table 3). Nineteen baseline items and four change scores stood out in terms of explaining medium or large ESs. Five of the baseline items and none of the change scores explained a small ES of unique variance in the regression models predicting global physical or mental health.

\section{Sampling-of-experience items}

Nine of the 14 baseline items and nine of the 14 change scores explained at least a small ES of variance in the MANCOVAs (Table 4). Five baseline items and no change scores stood out in terms of explaining medium or large ESs. Six of the baseline items and their change scores explained a small ES of unique variance in the regression models predicting global physical or mental health.

\section{Combinatory-algorithm items}

All seven of baseline items and all seven of the change scores explained at least a small ES of variance in the MANCOVAs (Table 5). Four baseline items and no change scores explained medium or large ESs. Three of the baseline items and their change scores explained a small ES of unique variance in the regression models predicting global physical or mental health. 
Table 3 Results of MANCOVA and Regression Analyses with Baseline and Change-Scores of Goal Delineation Items in the Frame of Reference Domain $(n=1391)$

\begin{tabular}{|c|c|c|c|c|c|c|c|c|c|c|c|c|c|c|}
\hline \multicolumn{15}{|c|}{ Results of MANCOVA and Regression Analyses with Baseline and Change-Scores of Goal Delineation Items in the Frame of Reference Domain ( $n=1,391$ ) } \\
\hline & $\begin{array}{l}\text { MANCOVA } \\
\text { among the } \mathrm{i} \\
\text { variables } \mathrm{H} \\
\mathrm{ADL} \text { chan }\end{array}$ & $\begin{array}{l}\text { 1: Includes } \\
\text { ndependent } \\
\text { ealthy Days } \\
\text { ge score* }\end{array}$ & $\begin{array}{r}\text { MANCOVA } \\
\text { among the } \\
\text { variables } \\
\text { Global Phy } \\
\text { change }\end{array}$ & $\begin{array}{l}\text { 2: Includes } \\
\text { idependent } \\
\text { PROMIS } \\
\text { ical Health } \\
\text { score* }^{*}\end{array}$ & $\begin{array}{r}\text { MANCOVA } \\
\text { among the in } \\
\text { variables } \\
\text { Global Mer } \\
\text { change }\end{array}$ & $\begin{array}{l}\text { 3: Includes } \\
\text { dependent } \\
\text { PROMIS } \\
\text { ital Health } \\
\text { score* }\end{array}$ & Regressior & $\begin{array}{l}\text { predicting } \\
\text { Health cha }\end{array}$ & $\begin{array}{l}\text { 'ROMIS Glob } \\
\text { nge score }{ }^{+}\end{array}$ & al Physical & Regressio & $\begin{array}{l}n \text { predicting } \\
\text { Health cha }\end{array}$ & $\begin{array}{l}\text { ROMIS Glot } \\
\text { nge score }{ }^{-}\end{array}$ & pal Mental \\
\hline \multirow{2}{*}{ Goal Delineation Item } & \multicolumn{2}{|c|}{$\mathrm{Eta}^{2}$} & \multicolumn{2}{|c|}{$\mathrm{Eta}^{2}$} & \multicolumn{2}{|c|}{$\mathrm{Eta}^{2}$} & \multicolumn{2}{|c|}{$\mathbf{R}^{2}$} & \multicolumn{2}{|c|}{$\begin{array}{l}\mathrm{R}^{2} \text { increment with } \\
\text { appraisal item }\end{array}$} & \multicolumn{2}{|c|}{$\mathbf{R}^{2}$} & \multicolumn{2}{|c|}{$\begin{array}{l}\mathbf{R}^{2} \text { increment with } \\
\text { appraisal item }\end{array}$} \\
\hline & $\begin{array}{c}\text { Baseline } \\
\text { Appraisal }\end{array}$ & $\begin{array}{l}\text { Change in } \\
\text { Appraisal }\end{array}$ & $\begin{array}{l}\text { Baseline } \\
\text { Appraisal }\end{array}$ & $\begin{array}{l}\text { Change in } \\
\text { Appraisal }\end{array}$ & $\begin{array}{c}\text { Baseline } \\
\text { Appraisal }\end{array}$ & $\begin{array}{l}\text { Change in } \\
\text { Appraisal }\end{array}$ & $\begin{array}{c}\text { Baseline } \\
\text { Appraisal }\end{array}$ & $\begin{array}{l}\text { Change in } \\
\text { Appraisal }\end{array}$ & $\begin{array}{c}\text { Baseline } \\
\text { Appraisal }\end{array}$ & $\begin{array}{l}\text { Change in } \\
\text { Appraisal }\end{array}$ & $\begin{array}{c}\text { Baseline } \\
\text { Appraisal }\end{array}$ & $\begin{array}{l}\text { Change in } \\
\text { Appraisal }\end{array}$ & $\begin{array}{l}\text { Baseline } \\
\text { Appraisal }\end{array}$ & $\begin{array}{l}\text { Change in } \\
\text { Appraisal }\end{array}$ \\
\hline Living conditions & 0.05 & 0.01 & 0.05 & 0.01 & 0.05 & 0.03 & 0.09 & 0.09 & 0.00 & 0.00 & 0.01 & 0.02 & 0.00 & 0.01 \\
\hline Keeping up at work & 0.13 & 0.01 & 0.13 & 0.02 & 0.13 & 0.08 & 0.09 & 0.09 & 0.00 & 0.00 & 0.01 & 0.02 & 0.00 & 0.01 \\
\hline Unfinished business & 0.06 & 0.02 & 0.06 & 0.02 & 0.06 & 0.04 & 0.10 & 0.09 & 0.01 & 0.01 & 0.01 & 0.02 & 0.00 & 0.01 \\
\hline Prepare loved ones & 0.07 & 0.02 & 0.07 & 0.02 & 0.07 & 0.05 & 0.09 & 0.09 & 0.00 & 0.00 & 0.01 & 0.02 & 0.00 & 0.00 \\
\hline Resolve practical problems & 0.17 & 0.02 & 0.17 & 0.02 & 0.18 & 0.11 & 0.09 & 0.09 & 0.01 & 0.00 & 0.03 & 0.04 & 0.02 & 0.03 \\
\hline Participate in upcoming & 0.02 & 0.02 & 0.02 & 0.02 & 0.02 & 0.02 & 0.09 & 0.09 & 0.01 & 0.00 & 0.02 & 0.01 & 0.00 & 0.00 \\
\hline Accomplish job & 0.24 & 0.02 & 0.24 & 0.02 & 0.24 & 0.15 & 0.09 & 0.09 & 0.01 & 0.00 & 0.01 & 0.01 & 0.00 & 0.00 \\
\hline Stay in current home & 0.07 & 0.02 & 0.07 & 0.02 & 0.07 & 0.05 & 0.09 & 0.09 & 0.00 & 0.00 & 0.01 & 0.01 & 0.00 & 0.00 \\
\hline Free of regrets & 0.01 & 0.01 & 0.01 & 0.01 & 0.01 & 0.01 & 0.09 & 0.09 & 0.00 & 0.00 & 0.01 & 0.02 & 0.00 & 0.01 \\
\hline Help with health & 0.15 & 0.03 & 0.14 & 0.04 & 0.14 & 0.10 & 0.09 & 0.10 & 0.00 & 0.02 & 0.02 & 0.02 & 0.01 & 0.01 \\
\hline Improve relationship & 0.04 & 0.01 & 0.04 & 0.01 & 0.04 & 0.03 & 0.09 & 0.09 & 0.01 & 0.00 & 0.02 & 0.03 & 0.01 & 0.01 \\
\hline Spiritual growth & 0.05 & 0.02 & 0.05 & 0.02 & 0.05 & 0.04 & 0.09 & 0.09 & 0.00 & 0.01 & 0.01 & 0.02 & 0.00 & 0.00 \\
\hline Community contributions & 0.01 & 0.01 & 0.01 & 0.02 & 0.01 & 0.01 & 0.09 & 0.09 & 0.00 & 0.00 & 0.01 & 0.01 & 0.00 & 0.00 \\
\hline Resolve money problems & 0.23 & 0.03 & 0.23 & 0.03 & 0.23 & 0.15 & 0.09 & 0.09 & 0.01 & 0.00 & 0.01 & 0.01 & 0.00 & 0.00 \\
\hline Balance & 0.08 & 0.01 & 0.08 & 0.01 & 0.09 & 0.05 & 0.09 & 0.09 & 0.01 & 0.00 & 0.01 & 0.02 & 0.00 & 0.00 \\
\hline Improve mood & 0.09 & 0.01 & 0.09 & 0.02 & 0.10 & 0.06 & 0.09 & 0.09 & 0.01 & 0.01 & 0.02 & 0.07 & 0.01 & 0.06 \\
\hline Family conflicts & 0.06 & 0.02 & 0.06 & 0.03 & 0.06 & 0.05 & 0.09 & 0.09 & 0.00 & 0.00 & 0.01 & 0.03 & 0.00 & 0.02 \\
\hline Romance & 0.04 & 0.01 & 0.04 & 0.01 & 0.04 & 0.03 & 0.09 & 0.09 & 0.00 & 0.00 & 0.01 & 0.02 & 0.00 & 0.01 \\
\hline Continue to drive & 0.03 & 0.01 & 0.03 & 0.01 & 0.03 & 0.02 & 0.09 & 0.09 & 0.00 & 0.00 & 0.01 & 0.01 & 0.00 & 0.00 \\
\hline Break from responsibility & 0.07 & 0.02 & 0.08 & 0.02 & 0.08 & 0.05 & 0.09 & 0.10 & 0.00 & 0.01 & 0.02 & 0.02 & 0.01 & 0.01 \\
\hline Live with discomfort & 0.07 & 0.01 & 0.08 & 0.01 & 0.07 & 0.05 & 0.09 & 0.09 & 0.01 & 0.01 & 0.01 & 0.02 & 0.00 & 0.01 \\
\hline Reduce help & 0.12 & 0.02 & 0.12 & 0.01 & 0.12 & 0.08 & 0.09 & 0.09 & 0.01 & 0.00 & 0.01 & 0.02 & 0.00 & 0.01 \\
\hline Get out of rut & 0.08 & 0.02 & 0.08 & 0.02 & 0.08 & 0.06 & 0.09 & 0.09 & 0.01 & 0.00 & 0.01 & 0.03 & 0.00 & 0.02 \\
\hline Solve healthcare problems & 0.10 & 0.02 & 0.11 & 0.02 & 0.10 & 0.07 & 0.09 & 0.09 & 0.01 & 0.01 & 0.01 & 0.02 & 0.00 & 0.01 \\
\hline Improve health & 0.04 & 0.02 & 0.04 & 0.01 & 0.04 & 0.03 & 0.10 & 0.09 & 0.01 & 0.00 & 0.02 & 0.02 & 0.01 & 0.01 \\
\hline Role problems & 0.07 & 0.01 & 0.07 & 0.01 & 0.08 & 0.05 & 0.09 & 0.09 & 0.00 & 0.01 & 0.02 & 0.04 & 0.01 & 0.03 \\
\hline Maintain healthcare & 0.04 & 0.02 & 0.04 & 0.02 & 0.04 & 0.03 & 0.09 & 0.09 & 0.00 & 0.00 & 0.01 & 0.02 & 0.00 & 0.01 \\
\hline Keep up activities & 0.02 & 0.02 & 0.02 & 0.02 & 0.02 & 0.02 & 0.10 & 0.09 & 0.01 & 0.01 & 0.01 & 0.01 & 0.00 & 0.00 \\
\hline Accept others & 0.02 & 0.01 & 0.02 & 0.01 & 0.02 & 0.02 & 0.09 & 0.09 & 0.00 & 0.00 & 0.01 & 0.01 & 0.00 & 0.00 \\
\hline Feel settled & 0.06 & 0.02 & 0.06 & 0.02 & 0.06 & 0.04 & 0.09 & 0.09 & 0.00 & 0.00 & 0.02 & 0.01 & 0.01 & 0.00 \\
\hline Reduce doctor time & 0.09 & 0.02 & 0.09 & 0.03 & 0.09 & 0.06 & 0.09 & 0.10 & 0.00 & 0.01 & 0.01 & 0.01 & 0.00 & 0.00 \\
\hline Let go of expectations & 0.06 & 0.02 & 0.07 & 0.02 & 0.06 & 0.04 & 0.09 & 0.09 & 0.00 & 0.00 & 0.01 & 0.02 & 0.00 & 0.01 \\
\hline Stop house care & 0.05 & 0.01 & 0.04 & 0.02 & 0.05 & 0.03 & 0.09 & 0.09 & 0.00 & 0.01 & 0.02 & 0.02 & 0.01 & 0.01 \\
\hline
\end{tabular}

Conditional formatting indicates the magnitude of the effect size (ES), with the least saturated highlighting showing small ES, the middle saturation indicating a medium ES, and the most saturated indicating a

* Dependent variables: Goal Delineation Items; Independent Variables: region, gender, age, comorbidities, difficulty paying bills, whether working, whether retired, whether disabled

† Independent Variables: Goal Delineation item; 3 covariates of age, comorbidities, difficulty paying bills; \& Goal Delineation item's interactions with the covariates

\section{Standards-of-comparison items}

Eight of the nine baseline items and seven of the nine change scores explained at least a small ES of variance in the MANCOVAs (Table 6). No baseline items or change scores explained medium or large ESs. No baseline items and seven change scores explained at least a small ES of unique variance in the regression models (five small ES, two medium ES).

\section{Tally of item performance across $Q O L A P_{v 2}$ domains}

Comparing across the above results, Table 7 provides a tally of each appraisal item's performance across the five baseline and five change-score analyses. This tally shows separately, for all domains and items, in what proportion of the analyses each item showed at least a small ES in MANCOVA analyses $\left(\mathrm{Eta}^{2}\right.$ when appraisal used as a reflective variable) and in regression analyses $\left(R^{2}\right.$ when appraisal used as an explanatory variable). The column on the far right shows the maximum of the baselineand change-score performances, because both the baseline and change scores are independently important (i.e., the former help to understand individual differences cross-sectionally; the latter are sensitive to response-shift effects). This tally suggests that the vast majority (i.e., $80 \%$ ) of the QOLAP $_{\mathrm{v} 2}$ items perform well across the analyses presented (i.e., explain at least a small ES). Using a criterion of evidence of value in at least $60 \%$ of analyses (i.e., 3 out of 5 models), our results support retaining 15 out of 20 QOL Definition items; 29 of 33 Goal Delineation Items; 9 of 14 Sampling-of-Experience items; 7 of 9 Combinatory-Algorithm items; and 8 of 9 Standards-of-Comparison items. 
Table 4 Results of MANCOVA and Regression Analyses with Baseline and Change Scores of Items in the Sampling of Experience Domain $(n=1391)$

\begin{tabular}{|c|c|c|c|c|c|c|c|c|c|c|c|c|c|c|}
\hline \multicolumn{15}{|c|}{ Results of MANCOVA and Regression Analyses with Baseline and Change Scores of Items in the Sampling of Experience Domain ( $n=1,391)$} \\
\hline & \multicolumn{2}{|c|}{$\begin{array}{l}\text { MANCOVA 1: Includes } \\
\text { among the independent } \\
\text { variables Healthy Days } \\
\text { ADL change score* }\end{array}$} & \multicolumn{2}{|c|}{$\begin{array}{l}\text { MANCOVA 2: Includes } \\
\text { among the independent } \\
\text { variables PROMIS Global } \\
\text { Physical Health change } \\
\text { score* }\end{array}$} & \multicolumn{2}{|c|}{$\begin{array}{l}\text { MANCOVA 3: Includes } \\
\text { among the independent } \\
\text { variables PROMIS Global } \\
\text { Mental Health change } \\
\text { score* }\end{array}$} & Regressio & $\begin{array}{l}\text { n predicting } \\
\text { Health cha }\end{array}$ & $\begin{array}{l}\text { ROMIS Glob } \\
\text { nge scoret }\end{array}$ & | Physical & \multicolumn{4}{|c|}{$\begin{array}{l}\text { Regression predicting PROMIS Global Mental Health } \\
\text { change score }{ }^{+}\end{array}$} \\
\hline \multirow{2}{*}{ Sample of Experience Item } & \multicolumn{2}{|c|}{$\mathrm{Eta}^{2}$} & \multicolumn{2}{|c|}{$\mathrm{Eta}^{2}$} & \multicolumn{2}{|c|}{$\mathrm{Eta}^{2}$} & \multicolumn{2}{|c|}{$\mathrm{R}^{2}$} & \multicolumn{2}{|c|}{$\begin{array}{l}\mathbf{R}^{2} \text { increment with } \\
\text { appraisal item }\end{array}$} & \multicolumn{2}{|c|}{$\mathbf{R}^{2}$} & \multicolumn{2}{|c|}{$\begin{array}{l}\mathbf{R}^{2} \text { increment with } \\
\text { appraisal item }\end{array}$} \\
\hline & $\begin{array}{l}\text { Baseline } \\
\text { Appraisal }\end{array}$ & $\begin{array}{l}\text { Change in } \\
\text { Appraisal }\end{array}$ & $\begin{array}{c}\text { Baseline } \\
\text { Appraisal }\end{array}$ & $\begin{array}{l}\text { Change in } \\
\text { Appraisal }\end{array}$ & $\begin{array}{c}\text { Baseline } \\
\text { Appraisal }\end{array}$ & $\begin{array}{l}\text { Change in } \\
\text { Appraisal }\end{array}$ & $\begin{array}{c}\text { Baseline } \\
\text { Appraisal }\end{array}$ & $\begin{array}{l}\text { Change in } \\
\text { Appraisal }\end{array}$ & $\begin{array}{c}\text { Baseline } \\
\text { Appraisal }\end{array}$ & $\begin{array}{l}\text { Change in } \\
\text { Appraisal }\end{array}$ & $\begin{array}{l}\text { Baseline } \\
\text { Appraisal }\end{array}$ & $\begin{array}{l}\text { Change in } \\
\text { Appraisal }\end{array}$ & $\begin{array}{l}\text { Baseline } \\
\text { Appraisal }\end{array}$ & $\begin{array}{l}\text { Change in } \\
\text { Appraisal }\end{array}$ \\
\hline Worst moments & 0.08 & 0.01 & 0.09 & 0.01 & 0.09 & 0.06 & 0.10 & 0.09 & 0.02 & 0.00 & 0.02 & 0.07 & 0.01 & 0.05 \\
\hline Emphasize positive & 0.07 & 0.02 & 0.08 & 0.02 & 0.07 & 0.08 & 0.10 & 0.09 & 0.02 & 0.00 & 0.02 & 0.08 & 0.01 & 0.07 \\
\hline Recent few weeks & 0.02 & 0.01 & 0.02 & 0.01 & 0.02 & 0.01 & 0.09 & 0.09 & 0.00 & 0.00 & 0.01 & 0.01 & 0.00 & 0.00 \\
\hline Relevant past 3 mo. & 0.03 & 0.01 & 0.03 & 0.01 & 0.03 & 0.01 & 0.09 & 0.09 & 0.00 & 0.00 & 0.01 & 0.02 & 0.00 & 0.01 \\
\hline Balance positive/negative & 0.03 & 0.01 & 0.04 & 0.01 & 0.03 & 0.02 & 0.10 & 0.09 & 0.01 & 0.00 & 0.02 & 0.03 & 0.01 & 0.02 \\
\hline Recent flare-ups & 0.11 & 0.02 & 0.11 & 0.02 & 0.11 & 0.04 & 0.10 & 0.09 & 0.01 & 0.01 & 0.01 & 0.03 & 0.00 & 0.02 \\
\hline Future & 0.01 & 0.02 & 0.01 & 0.02 & 0.01 & 0.02 & 0.09 & 0.09 & 0.00 & 0.00 & 0.01 & 0.02 & 0.00 & 0.01 \\
\hline Focus on health & 0.12 & 0.02 & 0.11 & 0.02 & 0.12 & 0.02 & 0.10 & 0.10 & 0.01 & 0.01 & 0.02 & 0.02 & 0.01 & 0.01 \\
\hline Relationships & 0.01 & 0.02 & 0.01 & 0.02 & 0.01 & 0.02 & 0.09 & 0.09 & 0.00 & 0.01 & 0.02 & 0.02 & 0.00 & 0.01 \\
\hline Doctor told & 0.06 & 0.02 & 0.07 & 0.01 & 0.06 & 0.01 & 0.10 & 0.09 & 0.01 & 0.00 & 0.01 & 0.01 & 0.00 & 0.00 \\
\hline Only for survey & 0.01 & 0.01 & 0.01 & 0.01 & 0.01 & 0.01 & 0.09 & 0.09 & 0.00 & 0.00 & 0.01 & 0.01 & 0.00 & 0.00 \\
\hline First reaction & 0.02 & 0.02 & 0.02 & 0.02 & 0.02 & 0.02 & 0.09 & 0.09 & 0.00 & 0.01 & 0.02 & 0.02 & 0.01 & 0.01 \\
\hline Not complain & 0.01 & 0.01 & 0.01 & 0.01 & 0.01 & 0.01 & 0.09 & 0.09 & 0.00 & 0.01 & 0.02 & 0.02 & 0.01 & 0.01 \\
\hline Seriousness & 0.04 & 0.02 & 0.04 & 0.02 & 0.04 & 0.03 & 0.09 & 0.09 & 0.00 & 0.01 & 0.01 & 0.02 & 0.00 & 0.01 \\
\hline
\end{tabular}

Conditional formatting indicates the magnitude of the effect size (ES), with the least saturated highlighting showing small ES, the middle saturation indicating a medium ES, and the most saturated indicating a large ES

* Dependent variables: Sampling of Experience Items; Independent Variables: region, gender, age, comorbidities, difficulty paying bills, whether working, whether retired, whether disabled

$\dagger$ Independent Variables: Sampling of Experience item; 3 covariates of age, comorbidities, difficulty paying bills; \& Sampling of Experience item's interactions with the covariates

Table 5 Results of MANCOVA and Regression Analyses with Baseline and Change Scores of Items in the Combinatory Algorithm Domain $(n=1391)$

\begin{tabular}{|c|c|c|c|c|c|c|c|c|c|c|c|c|c|c|}
\hline \multirow{3}{*}{ Combinatory Algorithm Item } & \multicolumn{2}{|c|}{\begin{tabular}{|c} 
MANCOVA 1: Includes \\
among the independent \\
variables Healthy Days ADL \\
change score*
\end{tabular}} & \multicolumn{2}{|c|}{$\begin{array}{l}\text { MANCOVA 2: Includes } \\
\text { among the independent } \\
\text { variables PROMIS Global } \\
\text { Physical Health change } \\
\text { score* }\end{array}$} & \multicolumn{2}{|c|}{$\begin{array}{l}\text { MANCOVA 3: Includes } \\
\text { among the independent } \\
\text { variables PROMIS Global } \\
\text { Mental Health change } \\
\text { score* }\end{array}$} & \multicolumn{4}{|c|}{$\begin{array}{l}\text { Regression predicting PROMIS Global Physical Health } \\
\text { change score }{ }^{+}\end{array}$} & \multicolumn{4}{|c|}{$\begin{array}{l}\text { Regression predicting PROMIS Global Mental Health } \\
\text { change score }{ }^{\dagger}\end{array}$} \\
\hline & \multicolumn{2}{|c|}{ Eta $^{2}$} & \multicolumn{2}{|c|}{$\mathrm{Eta}^{2}$} & \multicolumn{2}{|c|}{$\mathrm{Eta}^{2}$} & \multicolumn{2}{|c|}{$\mathrm{R}^{2}$} & \multicolumn{2}{|c|}{$\begin{array}{l}R^{2} \text { increment with } \\
\text { appraisal item }\end{array}$} & \multicolumn{2}{|c|}{$\mathrm{R}^{2}$} & \multicolumn{2}{|c|}{$\begin{array}{l}\mathrm{R}^{2} \text { increment with } \\
\text { appraisal item }\end{array}$} \\
\hline & $\begin{array}{c}\text { Baseline } \\
\text { Appraisal }\end{array}$ & \begin{tabular}{l|l} 
Change in & \\
Appraisal &
\end{tabular} & $\begin{array}{c}\text { Baseline } \\
\text { Appraisal }\end{array}$ & $\begin{array}{l}\text { Change in } \\
\text { Appraisal }\end{array}$ & $\begin{array}{c}\text { Baseline } \\
\text { Appraisal }\end{array}$ & $\begin{array}{l}\text { Change in } \\
\text { Appraisal }\end{array}$ & $\begin{array}{c}\text { Baseline } \\
\text { Appraisal }\end{array}$ & $\begin{array}{l}\text { Change in } \\
\text { Appraisal }\end{array}$ & $\begin{array}{c}\text { Baseline } \\
\text { Appraisal }\end{array}$ & $\begin{array}{l}\text { Change in } \\
\text { Appraisal }\end{array}$ & $\begin{array}{l}\text { Baseline } \\
\text { Appraisal }\end{array}$ & $\begin{array}{l}\text { Change in } \\
\text { Appraisal }\end{array}$ & $\begin{array}{l}\text { Baseline } \\
\text { Appraisal }\end{array}$ & $\begin{array}{l}\text { Change in } \\
\text { Appraisal }\end{array}$ \\
\hline Negatives more important & 0.06 & 0.02 & 0.06 & 0.02 & 0.07 & 0.05 & 0.09 & 0.09 & 0.01 & 0.01 & 0.03 & 0.09 & 0.02 & 0.08 \\
\hline Determined by others & 0.01 & 0.02 & 0.01 & 0.02 & 0.01 & 0.02 & 0.09 & 0.09 & 0.00 & 0.00 & 0.02 & 0.09 & 0.01 & 0.08 \\
\hline Things better & 0.07 & 0.02 & 0.07 & 0.01 & 0.07 & 0.06 & 0.10 & 0.09 & 0.01 & 0.01 & 0.02 & 0.09 & 0.01 & 0.08 \\
\hline Gotten used to & 0.01 & 0.02 & 0.01 & 0.01 & 0.01 & 0.02 & 0.09 & 0.09 & 0.00 & 0.00 & 0.01 & 0.09 & 0.00 & 0.08 \\
\hline Ups and downs & 0.10 & 0.02 & 0.10 & 0.02 & 0.10 & 0.04 & 0.09 & 0.09 & 0.00 & 0.00 & 0.02 & 0.09 & 0.01 & 0.08 \\
\hline Keep up mood & 0.05 & 0.02 & 0.06 & 0.02 & 0.06 & 0.06 & 0.10 & 0.09 & 0.01 & 0.00 & 0.02 & 0.09 & 0.01 & 0.08 \\
\hline Recent events & 0.04 & 0.01 & 0.04 & 0.01 & 0.04 & 0.03 & 0.09 & 0.09 & 0.00 & 0.01 & 0.02 & 0.09 & 0.01 & 0.08 \\
\hline Obligations not accomplishments & 0.04 & 0.01 & 0.04 & 0.01 & 0.04 & 0.02 & 0.09 & 0.09 & 0.01 & 0.00 & 0.01 & 0.09 & 0.00 & 0.08 \\
\hline Recent changes & 0.03 & 0.01 & 0.03 & 0.02 & 0.04 & 0.03 & 0.09 & 0.10 & 0.01 & 0.02 & 0.02 & 0.10 & 0.01 & 0.09 \\
\hline
\end{tabular}

Conditional formatting indicates the magnitude of the effect size (ES), with the least saturated highlighting showing small ES, the middle saturation indicating a medium ES, and the most saturated indicating a large ES

* Dependent variables: Combinatory Algorithm Items; Independent Variables: region, gender, age, comorbidities, difficulty paying bills, whether working, whether retired, whether disabled

† Independent Variables: Combinatory Algorithm item; 3 covariates of age, comorbidities, difficulty paying bills; \& Combinatory Algorithm item's interactions with the covariates 
Table 6 Results of MANCOVA and Regression Analyses with Baseline and Change Scores onltems in the Standards of Comparison Domain $(n=1391)$

\begin{tabular}{|c|c|c|c|c|c|c|c|c|c|c|c|c|c|c|}
\hline \multirow{3}{*}{ Standards of Comparison Item } & \multicolumn{2}{|c|}{$\begin{array}{l}\text { MANCOVA 1: Includes } \\
\text { among the independent } \\
\text { variables Healthy Days } \\
\text { ADL change score* }\end{array}$} & \multicolumn{2}{|c|}{$\begin{array}{l}\text { MANCOVA 2: Includes } \\
\text { among the independent } \\
\text { variables PROMIS Global } \\
\text { Physical Health change } \\
\text { score* }\end{array}$} & \multicolumn{2}{|c|}{$\begin{array}{l}\text { MANCOVA 3: Includes } \\
\text { among the independent } \\
\text { variables PROMIS Global } \\
\text { Mental Health change } \\
\text { score* }\end{array}$} & \multicolumn{4}{|c|}{$\begin{array}{l}\text { Regression predicting PROMIS Global Physical } \\
\text { Health change score }{ }^{+}\end{array}$} & \multicolumn{4}{|c|}{$\begin{array}{l}\text { Regression predicting PROMIS Global Mental } \\
\text { Health change score }{ }^{\dagger}\end{array}$} \\
\hline & \multicolumn{2}{|c|}{$\mathrm{Eta}^{2}$} & \multicolumn{2}{|c|}{$\mathrm{Eta}^{2}$} & \multicolumn{2}{|c|}{$\mathrm{Eta}^{2}$} & \multicolumn{2}{|c|}{$\mathrm{R}^{2}$} & \multicolumn{2}{|c|}{$\begin{array}{l}R^{2} \text { increment with } \\
\text { appraisal item }\end{array}$} & \multicolumn{2}{|c|}{$R^{2}$} & \multicolumn{2}{|c|}{$\begin{array}{l}\mathbf{R}^{2} \text { increment with } \\
\text { appraisal item }\end{array}$} \\
\hline & $\begin{array}{c}\text { Baseline } \\
\text { Appraisal }\end{array}$ & $\begin{array}{l}\text { Change in } \\
\text { Appraisal }\end{array}$ & $\begin{array}{c}\text { Baseline } \\
\text { Appraisal }\end{array}$ & $\begin{array}{l}\text { Change in } \\
\text { Appraisal }\end{array}$ & $\begin{array}{l}\text { Baseline } \\
\text { Appraisal }\end{array}$ & $\begin{array}{l}\text { Change in } \\
\text { Appraisal }\end{array}$ & $\begin{array}{l}\text { Baseline } \\
\text { Appraisal }\end{array}$ & $\begin{array}{l}\text { Change in } \\
\text { Appraisal }\end{array}$ & $\begin{array}{l}\text { Baseline } \\
\text { Appraisal }\end{array}$ & $\begin{array}{l}\text { Change in } \\
\text { Appraisal }\end{array}$ & $\begin{array}{l}\text { Baseline } \\
\text { Appraisal }\end{array}$ & $\begin{array}{l}\text { Change in } \\
\text { Appraisal }\end{array}$ & $\begin{array}{l}\text { Baseline } \\
\text { Appraisal }\end{array}$ & $\begin{array}{l}\text { Change in } \\
\text { Appraisal }\end{array}$ \\
\hline Others with same condition & 0.02 & 0.02 & 0.02 & 0.02 & 0.03 & 0.02 & 0.088 & 0.094 & 0.003 & 0.009 & 0.013 & 0.058 & 0.002 & 0.047 \\
\hline Healthy others & 0.04 & 0.01 & 0.04 & 0.01 & 0.04 & 0.01 & 0.089 & 0.087 & 0.004 & 0.002 & 0.012 & 0.015 & 0.001 & 0.004 \\
\hline Doctor said & 0.04 & 0.02 & 0.04 & 0.02 & 0.04 & 0.02 & 0.093 & 0.093 & 0.008 & 0.008 & 0.017 & 0.078 & 0.006 & 0.067 \\
\hline Perfect health & 0.04 & 0.02 & 0.04 & 0.02 & 0.04 & 0.02 & 0.092 & 0.087 & 0.007 & 0.002 & 0.016 & 0.017 & 0.005 & 0.006 \\
\hline Life working for & 0.03 & 0.01 & 0.03 & 0.01 & 0.03 & 0.01 & 0.095 & 0.088 & 0.010 & 0.003 & 0.013 & 0.041 & 0.002 & 0.030 \\
\hline Way others see you & 0.02 & 0.01 & 0.02 & 0.01 & 0.02 & 0.01 & 0.089 & 0.086 & 0.004 & 0.001 & 0.013 & 0.062 & 0.002 & 0.051 \\
\hline People your age & 0.03 & 0.01 & 0.03 & 0.01 & 0.04 & 0.02 & 0.088 & 0.090 & 0.003 & 0.005 & 0.014 & 0.034 & 0.003 & 0.023 \\
\hline Time before health condition & 0.03 & 0.01 & 0.03 & 0.02 & 0.04 & 0.02 & 0.088 & 0.087 & 0.003 & 0.002 & 0.018 & 0.024 & 0.007 & 0.013 \\
\hline Family treated for same health condition & 0.02 & 0.01 & 0.02 & 0.01 & 0.02 & 0.01 & 0.087 & 0.102 & 0.002 & 0.017 & 0.012 & 0.031 & 0.001 & 0.020 \\
\hline
\end{tabular}

Conditional formatting indicates the magnitude of the effect size (ES), with the least saturated highlighting showing small ES, the middle saturation indicating a medium ES, and the most saturated indicating a large ES

* Dependent variables: Standards of Comparison Items; Independent Variables: region, gender, age, comorbidities, difficulty paying bills, whether working, whether retired, whether disabled

† Independent Variables: Standards of Comparison item; 3 covariates of age, comorbidities, difficulty paying bills; \& Standards of Comparison item's interactions with the covariates

\section{Discussion}

The present study provides intelligence about the cross-sectional and longitudinal informativeness of the QOLAP $_{\mathrm{v} 2}$ items across domains. For many investigators, an 85 -item measure is prohibitively long. Results of the present study can thus be useful for creating 'discretionary' short forms rather than a one-size-fitsall short-form solution. Given the fact that appraisal items are used in MANCOVAs as dependent variables, we would expect explained variance associated with a given item would be greater in the MANCOVAs than in the regressions because the former each focus on multiple predictors explaining an appraisal item. In contrast, in the regressions, appraisal items were more narrowly considered because they were tested only for their predictive power in accounting for a single dependent variable.

Since this idiometric measure [25] is intended to amplify individual differences in the cognitive processes underlying QOL, and respondent populations are expected to differ in the range and predominant cognitive processes used, it would make sense that short forms of the QOLAP ${ }_{\mathrm{v} 2}$ would be chosen to vary by study population. Patient populations differ in the inter-relationships of appraisal items, varying as a function of population differences in circumstances, background, and experiences [25].

An important distinction in this idiometric validation study is that the end result is not a "static short form" or a "computerized adaptive test" but rather an heuristic. Results of the present study provide heuristics to support investigators' liberty in selecting the best brief subset of items to fit their study aim. Those that performed less well would not be retained. In this context of idiometric measurement, investigators might select items that appear relevant to their study population on the basis of not only item performance shown herein and inter-item correlations shown elsewhere [25], but also by considering the unique circumstances of their study sample, research questions, intervention, etc. that they wish to amplify via the appraisal items. The 85 items included in the QOLAP $_{\mathrm{v} 2}$ represent research done on a broad range of patient groups using mixed methods and comprehensive study to generate the closed-ended items $[16,17,19,20,22,23,25,28]$. We thus believe the measure is a relatively complete set of cognitiveappraisal processes. It is, however, possible that specific study populations warrant item modification or development so piloting the selected QOLAP $_{\mathrm{v} 2} \mathrm{SF}$ items would be warranted. Finally, if a full study of the "three R's" of response shift is not a primary focus, one might select only a subset of the $\mathrm{QOLAP}_{\mathrm{v} 2}$ domains.

Information on QOL appraisal can be analyzed either at the item level [17] or with component scores derived from sample-specific principal components analysis [3, 16, 28]. Accordingly, such a discretionary approach to short-form creation is compatible with this general analytic paradigm. Since this approach is not standard procedure for patient-reported outcomes in general, an example of how one might go about making such a short form seems warranted.

By way of example, for a nationwide longitudinal study of healthy and chronically-ill people, we used a QOLAP $_{\mathrm{v} 2}$ short form comprised of six Goal-Delineation 
Table 7 Tallied Summary of Results

\begin{tabular}{|c|c|c|c|c|c|c|c|}
\hline \multicolumn{8}{|c|}{ Tallied Summary of Results } \\
\hline \multirow[b]{2}{*}{ Appraisal Items } & \multicolumn{2}{|c|}{ Baseline } & \multicolumn{4}{|c|}{ Change } & \multirow[b]{2}{*}{ Maximum \% } \\
\hline & $\begin{array}{c}\text { Eta2 }>0.02 \text { when } \\
\text { appraisal used } \\
\text { as reflective } \\
\text { variable }\end{array}$ & $\begin{array}{l}\text { R2 increment } \\
>0.01 \text { when } \\
\text { appraisal used } \\
\text { as explanatory } \\
\text { variable }\end{array}$ & $\begin{array}{c}\% \text { over } \\
\text { threshold } \\
\text { among Baseline } \\
\text { results }{ }^{\Psi}\end{array}$ & $\begin{array}{c}\text { Eta2 }>0.02 \text { when } \\
\text { appraisal used } \\
\text { as reflective } \\
\text { variable }\end{array}$ & $\begin{array}{l}\mathrm{R} 2 \text { increment } \\
>0.01 \text { when } \\
\text { appraisal used } \\
\text { as explanatory } \\
\text { variable }\end{array}$ & $\begin{array}{c}\% \text { over } \\
\text { threshold } \\
\text { among change } \\
\text { results }{ }^{\psi}\end{array}$ & \\
\hline \multicolumn{8}{|l|}{ QOL Definition item } \\
\hline Worry-free & 0 & 0 & $0 \%$ & 0 & 0 & $0 \%$ & $0 \%$ \\
\hline Accomplish job & 3 & 0 & $60 \%$ & 0 & 0 & $0 \%$ & $60 \%$ \\
\hline Well-off & 3 & 0 & $60 \%$ & 0 & 0 & $0 \%$ & $60 \%$ \\
\hline Perfect health & 3 & 0 & $60 \%$ & 0 & 0 & $0 \%$ & $60 \%$ \\
\hline Living for today & 0 & 0 & $0 \%$ & 0 & 0 & $0 \%$ & $0 \%$ \\
\hline Family time & 3 & 0 & $60 \%$ & 0 & 0 & $0 \%$ & $60 \%$ \\
\hline Not rely on others & 3 & 0 & $60 \%$ & 0 & 0 & $0 \%$ & $60 \%$ \\
\hline Legacy & 0 & 0 & $0 \%$ & 0 & 0 & $0 \%$ & $0 \%$ \\
\hline Do for others & 0 & 0 & $0 \%$ & 3 & 0 & $60 \%$ & $60 \%$ \\
\hline Healthy lifestyle & 3 & 0 & $60 \%$ & 3 & 0 & $60 \%$ & $60 \%$ \\
\hline Faith & 3 & 0 & $60 \%$ & 3 & 0 & $60 \%$ & $60 \%$ \\
\hline Calm & 1 & 0 & $\square \quad 20 \%$ & 3 & 0 & $60 \%$ & $60 \%$ \\
\hline Independence & 3 & 0 & $60 \%$ & 3 & 0 & $60 \%$ & $60 \%$ \\
\hline No regret & 0 & 0 & $0 \%$ & 0 & 0 & $0 \%$ & $0 \%$ \\
\hline Children's successes & 3 & 0 & $60 \%$ & 0 & 0 & $0 \%$ & $60 \%$ \\
\hline Romance & 3 & 0 & $60 \%$ & 0 & 0 & $0 \%$ & $60 \%$ \\
\hline Leisure & 3 & 0 & $60 \%$ & 3 & 0 & $60 \%$ & $60 \%$ \\
\hline Responsibilities & 3 & 0 & $60 \%$ & 0 & 0 & $0 \%$ & $60 \%$ \\
\hline Family problems & 3 & 0 & $60 \%$ & 0 & 0 & $0 \%$ & $60 \%$ \\
\hline Accepting myself & 0 & 0 & $0 \%$ & 0 & 0 & $0 \%$ & $0 \%$ \\
\hline \multicolumn{8}{|l|}{ Goal Delineation Item } \\
\hline Living conditions & 3 & 0 & $60 \%$ & 1 & 0 & $\square \quad 20 \%$ & $60 \%$ \\
\hline Keeping up at work & 3 & 0 & $60 \%$ & 1 & 1 & $40 \%$ & $60 \%$ \\
\hline Unfinished business & 3 & 1 & $80 \%$ & 3 & 0 & $60 \%$ & $80 \%$ \\
\hline Prepare loved ones & 3 & 0 & $60 \%$ & 1 & 0 & $\square \quad 20 \%$ & $60 \%$ \\
\hline Resolve practical problems & 3 & 1 & $80 \%$ & 2 & 1 & $60 \%$ & $80 \%$ \\
\hline Participate in upcoming & 3 & 0 & $60 \%$ & 1 & 0 & $\square \quad 20 \%$ & $60 \%$ \\
\hline Accomplish job & 3 & 0 & $60 \%$ & 3 & 0 & $60 \%$ & $60 \%$ \\
\hline Stay in current home & 3 & 0 & $60 \%$ & 1 & 0 & $\square \quad 20 \%$ & $60 \%$ \\
\hline Free of regrets & 0 & 0 & $0 \%$ & 0 & 0 & $0 \%$ & $0 \%$ \\
\hline Help with health & 3 & 0 & $60 \%$ & 3 & 2 & $100 \%$ & $100 \%$ \\
\hline Improve relationship & 3 & 0 & $60 \%$ & 1 & 1 & $40 \%$ & $60 \%$ \\
\hline Spiritual growth & 3 & 0 & $60 \%$ & 1 & 0 & $\square \quad 20 \%$ & $60 \%$ \\
\hline Community contributions & 0 & 0 & $0 \%$ & 0 & 0 & $0 \%$ & $0 \%$ \\
\hline Resolve money problems & 3 & 0 & $60 \%$ & 3 & 0 & $60 \%$ & $60 \%$ \\
\hline Balance & 3 & 0 & $60 \%$ & 1 & 0 & $\square \quad 20 \%$ & $60 \%$ \\
\hline Improve mood & 3 & 1 & $80 \%$ & 1 & 1 & $40 \%$ & $80 \%$ \\
\hline Family conflicts & 3 & 0 & $60 \%$ & 3 & 1 & $80 \%$ & $80 \%$ \\
\hline Romance & 3 & 0 & $60 \%$ & 1 & 0 & $\square \quad 20 \%$ & $60 \%$ \\
\hline Continue to drive & 3 & 0 & $60 \%$ & 1 & 0 & $\square \quad 20 \%$ & $60 \%$ \\
\hline Break from responsibility & 3 & 0 & $60 \%$ & 1 & 2 & $60 \%$ & $60 \%$ \\
\hline Live with discomfort & 3 & 0 & $60 \%$ & 1 & 0 & $\square \quad 20 \%$ & $60 \%$ \\
\hline Reduce help & 3 & 0 & $60 \%$ & 1 & 0 & $\square \quad 20 \%$ & $60 \%$ \\
\hline Get out of rut & 3 & 0 & $60 \%$ & 1 & 1 & $40 \%$ & $60 \%$ \\
\hline Solve healthcare problems & 3 & 0 & $60 \%$ & 1 & 0 & $\square \quad 20 \%$ & $60 \%$ \\
\hline Improve health & 3 & 1 & $80 \%$ & 1 & 0 & $\square \quad 20 \%$ & $80 \%$ \\
\hline Role problems & 3 & 0 & $60 \%$ & 1 & 1 & $40 \%$ & $60 \%$ \\
\hline Maintain healthcare & 3 & 0 & $60 \%$ & 1 & 0 & $\square \quad 20 \%$ & $60 \%$ \\
\hline Keep up activities & 0 & 1 & $\square \quad 20 \%$ & 2 & 0 & $40 \%$ & $40 \%$ \\
\hline Accept others & 0 & 0 & $0 \%$ & 0 & 0 & $0 \%$ & $0 \%$ \\
\hline Feel settled & 3 & 0 & $60 \%$ & 1 & 0 & $\square \quad 20 \%$ & $60 \%$ \\
\hline Reduce doctor time & 3 & 0 & $60 \%$ & 2 & 1 & $60 \%$ & $60 \%$ \\
\hline Let go of einypectations & 3 & 0 & $60 \%$ & 1 & 0 & $\square \quad 20 \%$ & $60 \%$ \\
\hline Stop house care & 3 & 0 & $60 \%$ & 2 & 0 & $40 \%$ & $60 \%$ \\
\hline
\end{tabular}


Table 7 Tallied Summary of Results (Continued)

\begin{tabular}{|c|c|c|c|c|c|c|c|}
\hline \multicolumn{8}{|l|}{ Sampling of Einyperience Item } \\
\hline Worst moments & 3 & 2 & $100 \%$ & 1 & 1 & $40 \%$ & $100 \%$ \\
\hline Emphasize positive & 3 & 2 & $100 \%$ & 2 & 1 & $60 \%$ & $100 \%$ \\
\hline Recent few weeks & 1 & 0 & $\square \quad 20 \%$ & 0 & 0 & $0 \%$ & $\square \quad 20 \%$ \\
\hline Relevant past $3 \mathrm{mo}$. & 3 & 0 & $60 \%$ & 0 & 0 & $0 \%$ & $60 \%$ \\
\hline Balance positive/negative & 3 & 1 & $80 \%$ & 1 & 1 & $40 \%$ & $80 \%$ \\
\hline Recent flare-ups & 3 & 1 & $80 \%$ & 3 & 1 & $80 \%$ & $80 \%$ \\
\hline Future & 0 & 0 & $0 \%$ & 3 & 0 & $60 \%$ & $60 \%$ \\
\hline Focus on health & 3 & 1 & $80 \%$ & 3 & 1 & $80 \%$ & $80 \%$ \\
\hline Relationships & 0 & 0 & $0 \%$ & 1 & 1 & $40 \%$ & $40 \%$ \\
\hline Doctor told & 3 & 1 & $80 \%$ & 0 & 0 & $0 \%$ & $80 \%$ \\
\hline Only for survey & 0 & 0 & $0 \%$ & 0 & 0 & $0 \%$ & $0 \%$ \\
\hline First reaction & 0 & 0 & $0 \%$ & 0 & 0 & $0 \%$ & $0 \%$ \\
\hline Not complain & 0 & 0 & $0 \%$ & 0 & 0 & $0 \%$ & $0 \%$ \\
\hline Seriousness & 3 & 0 & $60 \%$ & 3 & 1 & $80 \%$ & $80 \%$ \\
\hline \multicolumn{8}{|l|}{ Combinatory Algorithm Item } \\
\hline Negatives more important & 3 & 1 & $80 \%$ & 1 & 1 & $40 \%$ & $80 \%$ \\
\hline Determined by others & 0 & 0 & $0 \%$ & 0 & 1 & $\square \quad 20 \%$ & $\square \quad 20 \%$ \\
\hline Things better & 3 & 2 & $100 \%$ & 1 & 1 & $40 \%$ & $100 \%$ \\
\hline Gotten used to & 0 & 0 & $0 \%$ & 0 & 1 & $\square \quad 20 \%$ & $\square \quad 20 \%$ \\
\hline Ups and downs & 3 & 0 & $60 \%$ & 1 & 1 & $40 \%$ & $60 \%$ \\
\hline Keep up mood & 3 & 2 & $100 \%$ & 1 & 1 & $40 \%$ & $100 \%$ \\
\hline Recent events & 3 & 0 & $60 \%$ & 1 & 1 & $40 \%$ & $60 \%$ \\
\hline Obligations not accomplishments & 3 & 0 & $60 \%$ & 1 & 1 & $40 \%$ & $60 \%$ \\
\hline Recent changes & 3 & 0 & $60 \%$ & 2 & 2 & $80 \%$ & $80 \%$ \\
\hline \multicolumn{8}{|l|}{ Standards of Comparison } \\
\hline Others with same condition & 3 & 0 & $60 \%$ & 0 & 1 & $\square \quad 20 \%$ & $60 \%$ \\
\hline Healthy others & 3 & 0 & $60 \%$ & 0 & 0 & $0 \%$ & $60 \%$ \\
\hline Doctor said & 3 & 0 & $60 \%$ & 1 & 1 & $40 \%$ & $60 \%$ \\
\hline Perfect health & 3 & 0 & $60 \%$ & 0 & 0 & $0 \%$ & $60 \%$ \\
\hline Life working for & 3 & 0 & $60 \%$ & 0 & 1 & $\square \quad 20 \%$ & $60 \%$ \\
\hline Way others see you & 3 & 0 & $60 \%$ & 0 & 1 & $\square \quad 20 \%$ & $60 \%$ \\
\hline People your age & 3 & 0 & $60 \%$ & 0 & 1 & $\square \quad 20 \%$ & $60 \%$ \\
\hline Time before health condition & 3 & 0 & $60 \%$ & 0 & 1 & $\square \quad 20 \%$ & $60 \%$ \\
\hline Family treated for same condition & 0 & 0 & $0 \%$ & 0 & 2 & $40 \%$ & $40 \%$ \\
\hline
\end{tabular}

items that sampled across life areas of work, practical matters, healthcare, mood, independence, and new challenges. We included four Sampling-of-Experience items that performed well both cross-sectionally and over time using similar analyses on a patient sample similar to those presented herein. We included all the Standardsof-Comparison items due to experience in a number of patient populations where the items explained clinical differences between known groups [19, 42]. Finally, we opted to include all the Combinatory-Algorithm items because the study investigated coping with a difficult and unpredictable situation, and all of the Combinatory Algorithm items seemed pertinent. This 28 -item short form was viable given the good performance of the items in the QOLAP $_{\mathrm{v} 2}$ and covered the content that was hypothesized to be relevant to the study aims.

This study has advantages in terms of a robust sample size and a participant sample that is heterogeneous in terms of chronic medical condition and many demographic variables. Its limitations should, however, be acknowledged. First, the sample is less representative of non-Whites and of males, which may affect the generalizability of our findings. Second, since the sample specifically comprises medically-ill people and their caregivers, most of whom also have medical conditions, the generalizability of our findings to people with no health problems is unknown. Future research might replicate these analyses in a healthy comparison group sampled to represent national breakdowns in terms of gender and race, as well as other demographic characteristics.

\section{Conclusions}

In summary, results of the present study support the informativeness of the vast majority of QOLAP $_{\mathrm{v} 2}$ items. Based on this evidence base, we suggest that investigators select the most relevant items within each domain for their 'discretionary' short-form measure of QOL appraisal. By retaining the domain distinctions, they will be able to characterize the different aspects of response shift in their longitudinal study. It is also our hope that this study provides not only a methodological 'template' for short-form development of other idiometric measures, but also a different way of conceptualizing and characterizing item banks' for such measures. 


\section{Abbreviations}

ADL: Activities of daily living; BAl: Brief Appraisal Inventory; ES: Effect size; HIPAA: Health Insurance Portability and Accountability Act; MANCOVA: Multivariate analysis of covariance; PROMIS: Patient-Reported Outcome Measurement Information System; QOL: Quality of life; QOLAP: Quality of Life Appraisal Profile; QOLAPv2: QOLAP version 2; SD: Standard deviation

\section{Supplementary Information}

The online version contains supplementary material available at https:/doi. org/10.1186/s41687-021-00317-x.

Additional file 1 : Supplemental Table 1. Descriptive Statistics for Apprasial Items and QOL Outcomes. Supplemental Table 2. Results of Preliminary MANOVA Comparisons ${ }^{\varphi}$. Supplemental Table 3. Results of Preliminary Squared Correlation Coefficients at Baseline*. Supplemental Table 4. $95 \%$ Confidence Intervals for Variance Explained.

\section{Acknowledgements}

We are grateful to the people who participated in this study, and to Wesley Michael of Rare Patient Voice, LLC, for providing access to patients and caregivers in this study.

\section{Authors' contributions}

CES, RBD and BDR designed the research study. CES, RBS, and BDR analyzed the data. CES wrote the paper and RBS and BDR edited the manuscript. All authors read and approved the final manuscript.

\section{Funding}

This work was not funded by any external agency.

\section{Availability of data and materials}

The data used in these secondary analyses are confidential and thus not able to be shared.

\section{Declarations}

\section{Ethics approval and consent to participate}

All procedures performed in studies involving human participants were in accordance with the ethical standards of the institutional and/or national research committee and with the 1964 Helsinki declaration and its later amendments or comparable ethical standards. The study was reviewed and approved by the New England Review Board (NEIRB\#15-254). Informed consent was obtained from all individual participants included in the study.

\section{Consent for publication}

Not applicable.

\section{Competing interests}

All authors declare that they have no potential conflicts of interest and report no disclosures.

\section{Author details}

${ }^{1}$ DeltaQuest Foundation, Inc., 31 Mitchell Road, Concord, MA 01742, USA. ${ }^{2}$ Departments of Medicine and Orthopaedic Surgery, Tufts University Medical School, Boston, MA, USA. ${ }^{3}$ Department of Epidemiology and Population Health, Albert Einstein College of Medicine, Bronx, NY, USA

\section{Received: 23 December 2020 Accepted: 6 May 2021}

\section{Published online: 13 July 2021}

\section{References}

1. Sprangers, M. A. G., \& Schwartz, C. E. (1999). Integrating response shift into health-related quality of life research: A theoretical model. Social Science \& Medicine, 48(11), 1507-1515. https://doi.org/10.1016/S0277-9536(99)00045-3.

2. Rapkin, B. D., \& Schwartz, C. E. (2004). Toward a theoretical model of qualityof-life appraisal: Implications of findings from studies of response shift. Health and Quality of Life Outcomes, 2(1), 14. https://doi.org/10.1186/14777525-2-14.
3. Rapkin, B. D., \& Schwartz, C. E. (2019). Advancing quality-of-life research by deepening our understanding of response shift: A unifying theory of appraisal. Quality of Life Research, 28(10), 2623-2630. https://doi.org/10.1007/ s11136-019-02248-z.

4. Schwartz, C. E., \& Sprangers, M. A. G. (1999). Methodological approaches for assessing response shift in longitudinal health-related quality-of-life research. Social Science \& Medicine, 48(11), 1531-1548. https://doi.org/10.101 6/S0277-9536(99)00047-7.

5. Oort, F. J. (2005). Using structural equation modeling to detect response shifts and true change. Quality of Life Research, 14(3), 587-598. https://doi. org/10.1007/s11136-004-0830-y.

6. Mayo, N., Scott, C., \& Ahmed, S. (2009). Case management post-stroke did not induce response shift: The value of residuals. Journal of Clinical Epidemiology, 62, 1148-1156.

7. Li, Y., \& Rapkin, B. D. (2009). Classification and regression tree analysis to identify complex cognitive paths underlying quality of life response shifts: A study of individuals living with HIV/AIDS. Journal of Clinical Epidemiology, 62(11), 1138-1147. https://doi.org/10.1016/j.jclinepi.2009.03. 021.

8. Lix, L. M., Sajobi, T. T., Sawatzky, R., Liu, J., Mayo, N. E., Huang, Y., .. Bernstein, C. N. (2013). Relative importance measures for reprioritization response shift. Quality of Life Research, 22(4), 695-703. https://doi.org/10.1 007/s11136-012-0198-3.

9. Boucekine, M., Loundou, A., Baumstarck, K., Minaya-Flores, P., Pelletier, J., Ghattas, B., \& Auquier, P. (2013). Using the random forest method to detect a response shift in the quality of life of multiple sclerosis patients: A cohort study. BMC Medical Research Methodology, 13(1), 20. https://doi.org/10.11 86/1471-2288-13-20.

10. Sawatzky, R., Gadermann, A. M., Ratner, P. A., Zumbo, B., \& Lix, L. (2012). Identifying individuals with inflammatory bowel disease who experienced response shift: A latent class analysis. Quality of Life Research, 21, 33.

11. Guilleux, A., Blanchin, M., Vanier, A., Guillemin, F., Falissard, B., Schwartz, C. E., Sébille, V. (2015). Response shift algorithm in item response theory (ROSALI) for response shift detection with missing data in patient-reported outcomes in longitudinal clinical trials. Quality of Life Research, 24(3), 553564. https://doi.org/10.1007/s11136-014-0876-4.

12. Ring, L., Hofer, S., Heuston, F., Harris, D., \& O'Boyle, C. A. (2005). Response shift masks the treatment impact on patient reported outcomes: The example of individual quality of life in edentulous patients. Health and Quality of Life Outcomes, 3(1), 55. https://doi.org/10.1186/1477-7525-3-55.

13. Ruta, D. A., Garratt, A. M., Leng, M., Russell, I. T., \& MacDonald, L. M. (1994). A new approach to the measurement of quality of life. The Patient-Generated Index. Medical Care, 32(11), 1109-1126. https://doi.org/10.1097/00005650-1 99411000-00004.

14. Schwartz, C. E., \& Rapkin, B. D. (2004). Reconsidering the psychometrics of quality of life assessment in light of response shift and appraisal. Health and Quality of Life Outcomes, 2(1), 16. https://doi.org/10.1186/1477-7525-2-16.

15. Tourangeau, R., Rips, L. J., \& Rasinski, K. (2000). The psychology of survey response. Cambridge University Press. https://doi.org/10.1017/CBO978051181 9322.

16. Schwartz, C. E., Zhang, J., Stucky, B. D., Michael, W., \& Rapkin, B. D. (2020). Does response shift impact interpretation of change even among scales developed using item response theory? Journal of Patient-Reported Outcomes, 4(8), 8. https://doi.org/10.1186/s41687-019-0162-x.

17. Schwartz, C. E., Quaranto, B. R., Rapkin, B. D., Healy, B. C., Vollmer, T., \& Sprangers, M. A. G. (2014). Fluctuations in appraisal over time in the context of stable and non-stable health. Quality of Life Research, 23(1), 9-19. https:// doi.org/10.1007/s11136-013-0471-0.

18. Morganstern, B. A., Bernard, B., Dalbagni, G., Shabsigh, A., \& Rapkin, B. D. (2011). The psychological context of quality of life: A psychometric analysis of a novel idiographic measure of bladder cancer patients' personal goals and concerns prior to surgery. Health and Quality of Life Outcomes, 9(10), 10. https://doi.org/10.1186/1477-7525-9-10.

19. Schwartz, C. E, Zhang, J., Rapkin, B. D., \& Finkelstein, J. A. (2019) Reconsidering the minimally important difference: Evidence of instability over time and across groups. The Spine Journal, 19(4), 726-734. https://doi org/10.1016/j.spinee.2018.09.010.

20. Rapkin, B. D., Garcia, I., Michael, W., Zhang, J., \& Schwartz, C. E. (2016). Distinguishing appraisal and personality influences on quality of life in chronic illness: Introducing the Quality-of-Life Appraisal Profile version 2. Quality of Life Research, 26, 2815-2829. 
21. Rapkin, B. D., Garcia, I., Michael, W., Zhang, J., \& Schwartz, C. E. (2017). Development of a practical outcome measure to account for individual differences in quality-of-life appraisal: The Brief Appraisal Inventory. Quality of Life Research, 27(3), 823-833. https://doi.org/10.1007/s11136-017-1722-2.

22. Rapkin, B. D., \& Schwartz, C. E. (2016). Distilling the essence of appraisal: A mixed methods study of people with multiple sclerosis. Quality of Life Research, 25(4), 793-805. https://doi.org/10.1007/s11136-015-1119-z.

23. Schwartz, C. E., Li, J., \& Rapkin, B. D. (2016). Refining a web-based goal assessment interview: Item reduction based on reliability and predictive validity. Quality of Life Research, 25(9), 2201-2212. https://doi.org/10.1007/ s11136-016-1258-x

24. Schwartz, C. E., Finkelstein, J. A., \& Rapkin, B. D. (2017). Appraisal assessment in patient-reported outcome research: Methods for uncovering the personal context and meaning of quality of life. Quality of Life Research, 26(26), 545554. https://doi.org/10.1007/s11136-016-1476-2.

25. Schwartz, C. E., Stark, R. B., \& Rapkin, B. D. (2020). Capturing patient experience: Does quality-of-life appraisal entail a new class of measurement? Journal of Patient-Reported Outcomes, 4, 1-11.

26. Cohen, J. (1992). A power primer. Psychological Bulletin, 112(1), 155-159. https://doi.org/10.1037/0033-2909.112.1.155.

27. Oort, F. J., Visser, M. R. M., \& Sprangers, M. A. G. (2005). An application of structural equation modeling to detect response shifts and true change in quality of life data from cancer patients undergoing invasive surgery. Quality of Life Research, 14(3), 599-609. https://doi.org/10.1007/s11136-004-0831-X.

28. Schwartz, C. E., Michael, W., \& Rapkin, B. D. (2017). Resilience to health challenges is related to different ways of thinking: Mediators of quality of life in a heterogeneous rare-disease cohort. Quality of Life Research, 26(11), 3075-3088. https://doi.org/10.1007/s11136-017-1633-2.

29. Centers for Disease Control and Prevention. Measuring Healthy Days. Atlanta: CDC; 2000

30. Hays, R. D., Bjorner, J. B., Revicki, D. A., Spritzer, K. L., \& Cella, D. (2009). Development of physical and mental health summary scores from the patient-reported outcomes measurement information system (PROMIS) global items. Quality of Life Research, 18(7), 873-880. https://doi.org/10.1007/ s11136-009-9496-9.

31. Hanmer, J., \& Cherepanov, D. (2016). A single question about a respondent's perceived financial ability to pay monthly bills explains more variance in health utility scores than absolute income and assets questions. Quality of Life Research, 25(9), 2233-2237. https://doi.org/10.1007/s11136-016-1269-7.

32. Sangha, O., Stucki, G., Liang, M. H., Fossel, A. H., \& Katz, J. N. (2003). The selfadministered comorbidity questionnaire: A new method to assess comorbidity for clinical and health services research. Arthritis Care \& Research, 49(2), 156-163. https://doi.org/10.1002/art.10993.

33. US Region Map (2020). Source: https://yourfreetemplates.com/us-region-ma p-template. Accessed 20 Jan 2020.

34. Cohen, J. (1988). Statistical Power Analysis for the Behavioral Sciences. Lawrence Erlbaum Associates.

35. Allen, I. E., \& Seaman, C. A. (2007). Likert scales and data analyses. Quality Progress, 40(7), 64-65.

36. Svensson, E. (2001). Guidelines to statistical evaluation of data from rating scales and questionnaires. Journal of Rehabilitation Medicine, 33(1), 47-48. https://doi.org/10.1080/165019701300006542.

37. Harpe, S. E. (2015). How to analyze Likert and other rating scale data. Currents in Pharmacy Teaching \& Learning, 7(6), 836-850. https://doi.org/10.1 016/j.cptl.2015.08.001.

38. Hsu, T.-C., \& Feldt, L. S. (1969). The effect of limitations on the number of criterion score values on the significance level of the F-test. American Educational Research Journal, 6(4), 515-527.

39. Garson, G. D. (2012). Testing statistical assumptions. Statistical Associates Publishing.

40. IBM (2019). IBM SPSS statistics for windows, (26th ed., ). IBM Corp.

41. Core Team, R. (2017). R: A language and environment for statistical computing. R Foundation for Statistical Computing.

42. Schwartz, C. E., Powell, V. E., \& Rapkin, B. D. (2017). When global rating of change contradicts observed change: Examining appraisal processes underlying paradoxical responses over time. Quality of Life Research, 26(4), 847-857. https://doi.org/10.1007/s11136-016-1414-3.

\section{Publisher's Note}

Springer Nature remains neutral with regard to jurisdictional claims in published maps and institutional affiliations.

\section{Submit your manuscript to a SpringerOpen ${ }^{\circ}$ journal and benefit from:}

- Convenient online submission

- Rigorous peer review

- Open access: articles freely available online

- High visibility within the field

- Retaining the copyright to your article

Submit your next manuscript at $\boldsymbol{\nabla}$ springeropen.com 